\title{
The role of mandibular 3rd Molars on the incidence of Condylar Fractures - a clinical study.
}

\author{
Dr. Vivek G.K, MDS
}

\begin{abstract}
:
Aims: Condylar region of the mandible is the most vulnerable site to fracture due to its anatomical weakness. It has been noted that mandibular third molars may reduce the occurrence of condylar fractures. This study was conducted to verify this hypothesis.

Materials and methods: This retrospective study of records of 147 mandibular fracture patients treated during 5 year period during 2008 to 2013 were analyzed for the correlation between $3^{\text {rd }}$ molars and incidence of condyle fractures.

Results: Condylar fracture was two times greater in those with missing or completely erupted mandibular third molars as compared to those with unerupted ones ( $p<0.001)$, erupted mandibular third molar position can influence the occurrence of condylar fracture.

Conclusion:erupted mandibular third molars significantly increased the occurrence of condylar fractures.

Key words: unerupted mandibular third molars, condylar fractures.
\end{abstract}

\section{Introduction:}

The mandible is one of the most susceptible of the facial bones to fracture this is due to its relatively prominent position in relation to common injuring forces(1). Mandibular fractures follow a pattern, common to many injuries, in that young males are predominantly affected (2) The reported rate of occurrence of mandibular fractures is 11.5 per 100,000 people per year(3).Many investigators have reported that patients with unerupted mandibular third molars were more likely to have an angle fracture than those patients without unerupted mandibular third molars. This has been attributed to the decreased cross- sectional area of bone at the mandibular angle that contains the unerupted third molars(4-6). An inverse relationship was seen for condylar fractures patients with impacted mandibular third molars were less likely to have a condylar fracture than those without impacted ones (7-9). Whether incompletely erupted lower third molars without clinical symptoms should be surgically removed remain controversial(10). However, several authors $(4,11)$ recommended extraction of them in adolescents and young adults who frequently play contact sports because of the associated high incidence of mandibular angle fractures.

As the mandible is fractured more often at the condyle rather than at the angle in the absence of unerupted third molars, it may not be advantageous to extract the unerupted third molars as a protective measure against mandibular angle fracture, because the treatment of condylar fractures is more difficult and challenging than that of angle fractures $(12,13)$ The objective of this retrospective study was to determine the relationship between the occurrence of mandibular condylar fractures and the presence and absence of unerupted mandibular third molars.

\section{Materials \& method:}

A retrospective review of clinical and radiographic records of mandibular angle and condylar fracture cases managed in the maxillofacial unit from June 2009 to Dec 2013 was done. The study analyzed the presence of 3rd molars in these cases and their eruptive status. During this period of 5 years a total of 147 cases of mandibular fractures were treated in the center. These included 126 males and 21 females. There were 38 angle fractures and 56 condyle fractures in this series.In angle fractures cases 8 cases were isolated fractures, 30 with concomitant parasymphysis fracture. Amongst the 56 condyle fractures, there were 15 isolated fractures, 39 were associated with symphysis or parasymphysis and remaining 2 cases were bilateral condyle fracture cases.

\section{Results:}

The results showed 147 cases of mandibular fractures included 126 males and 21 females in the age range of 15-70 years with a mean age of 32(fig1). The number of angle fractures in the series was 38 out of 147,there were 17 fractures on left and 21 fractures on the, 27 of these fractures $(71 \%)$ showed the presence of impacted $3^{\text {rd }}$ molar in the side involved. 11 cases had erupted $3^{\text {rd }}$ molars $(28.9 \%)$.

Out of 56 cases of condyle fractures 24 were on left side and 30 were on right side and 2 cases had bilateral condyle fractures. on evaluation of status of $3^{\text {rd }}$ molar,39 cases $3^{\text {rd }}$ molars was fully erupted $(69.6 \%)$ 
and missing molars in 2 cases $(3.5 \%)$ and only in 13 cases(fig2,3,). there was an impacted $3^{\text {rd }}$ molar present $(23.2 \%)$.Also in relation to the classification of Pell and Gregory, the largest percentages corresponded to Class A $(65.4 \%)$ and Class B (30.8\%).According to the classification of Winter, $75 \%$ of the teeth had a vertical angulation, followed by $21.1 \%$ with mesioangular angulation.

All the data were analyzed using spearman's correlation coefficient test (fig:4), the test shows negligible correlation with respect to impacted $3^{\text {rd }}$ molar to condyle fracture cases.But there is a strong positive correlation between erupted $3^{\text {rd }}$ molars and condyle fracture cases of value $0.486(v)$ and $p$ value of $<0.001$, which is highly significant.

\section{Discussion:}

The condylar region of the mandible is one of the most common susceptible sites to fracture. In the present study more than $39 \%$ of mandibular fractures were noted at the condylar region. A biomechanical study by Kober et al (15) showed that this area is the weakest against the impact acting on the mandible, especially at the anterior region. The impact forces that cause condylar fractures transmit to the mandibular angle on the same side, which is biomechanically stronger than the condyle.In the group of condylar fractures, the results of this study agree with Duan et al. (16) in relation to the prevalence of an older population, but in relation to the predominant gender, which was male in this study. The greater predisposition of males was probably due to the fact that they are more exposed to the risk factors for facial trauma, such as road accidents and physical aggression.

Clinical investigations have implied that unerupted mandibular third molar is a risk factor for mandibular angle fractures (4-7). The reason for the higher risk of angle fractures in cases with unerupted mandibular third molars is thought to be that the mandibular angle is weakened by the decrease in bony space caused by presence of the tooth.

In the present study, mandibular condylar fractures were more than two times greater in those without unerupted mandibular third molars as compared to those with unerupted ones. Our findings come in agreement with other previous studies in that incompletely erupted mandibular third molars are preventive factors against condylar fractures (7-9). In the fractures associated with condylar ones, about $61 \%$ of them were in the symphysis and parasymphysis.

This study revealed that the risk of condylar fractures was also dependent on unerupted third molar position. The highest occurrence of condylar fracture was in class I and position A, as well as vertical impactions.

Clinically, patients with mandibular angle fractures generally do not experience severe postoperative complications. In contrast, condylar process fractures have a risk of functional disorders, such as malocclusion and decreased mandibular mobility, Several authors $(4,11,16,17,18)$ have suggested extraction of unerupted mandibular third molars in young sports-men as preventive measures against mandibular angle fractures, especially in contact sports. However, this treatment policy may possibly alter the biomechanical strength of the mandible and increases the risk of condylar fractures.

In terms of the precise reduction and fixation of mandibular fractures, difficulties are often encountered in repositioning the condylar fragments and performing accurate placement of the plates and screws (19), in addition there is the possibility of facial nerve injury $(20,21)$, excellent reduction and stable fixation in angle fractures are easily performed because the access and visibility to the angle fractures for plating is much better. Thus it might not be appropriate to strengthen the mandibular angle region and to make the mandible more vulnerable to condylar fractures by removing the unerupted third molars because the treatment of condylar fractures is more challenging than that of angle $(22,23)$.

\section{Conclusion}

The presence of impacted $3^{\text {rd }}$ molar is a risk factor for mandibular angle fracture and absence of it is may increase the risk of condyle fracture.

\section{References:}

[1]. Moore JR. Principles of Oral Surgery, 2nd edn. Manchester: Manchester University Press, $1976: 175$.

[2]. Wolujewicz MA. Fractures of the mandible involving impacted 3rd molar tooth: an analysis of 47 cases. Br J Surg 1980: $18: 125$.

[3]. Schwimmer A, Stern R, Kritchman D: Impacted third molars: A contributing factor in mandibular fractures in contact sports. Am J Sports Med 11:262,1983.

[4]. Tevepaugh DB, Dodson TB: Are mandibular third molars a risk factor for angle fractures? A retrospective cohort study. J Oral Maxillofac Surg 53:646, 1995.

[5]. Safdar N, Meechan JG: Relationship between fractures of the mandibular angle and the presence and state of eruption of the lower third molar. Oral Surg Oral Med Oral Pathol Oral Radiol Endod 1995;79:680-4

[6]. Tankersly K, Abubaker AO, Laskin DM: The relationship between presence of mandibular third molars and mandibular angle fractures. J Dent Res 1995;74:80 
The role of mandibular 3rd Molars on the incidence of Condylar Fractures - a clinical study.

[7]. David R. Halmos, Edward Ellis III and Thomas B. Dodson. Mandibular Third Molars and Angle Fractures. J Oral Maxillofac Surg 2004;62:1076-1081.

[8]. Joyce T Lee and Thomas B. Dodson, The Effect of Mandibular Third Molar Presence and Position on the Risk of an Angle Fracture J Oral Maxillofoc Surg 2000;58:394-398.

[9]. Jasser Ma'aita and Abdelwahhab Alwrikat Is the mandibular third molar a risk factor for mandibular angle fracture? Oral Surg Oral Med Oral Pathol Oral Radiol Endod 2000;89:143-6

[10]. Meisami T, Sojat A, Sandor GKB, Lawrence HP, Clokie CML. Impacted third molars and risk of angle fractures. Int J Oral Maxillofac Surg 2002;31:140-144.

[11]. Ugboko VI, Oginni FO, Owotade FJ. An investigation into the relationship between mandibular third molars and angle fractures in Nigerians. Br J Oral Maxillofac Surg 2000;38:427-9.

[12]. David R. Halmos, Edward Ellis III and Thomas B. Dodson. Mandibular Third Molars and Angle Fractures. J Oral Maxillofac Surg 2004; 62:1076-1081.

[13]. Lee JT, Dodson TB. The effect of mandibular third molar presence and position on the risk of an angle fracture. J Oral Maxillofac Surg 2000;58(4):394-398.

[14]. Hang RH, Prather J, Indresano AT. An epidemiologic survey of facial fractures and concomitant injuries. J Oral Maxillofac Surg 1990; 48 (9): 926-932.

[15]. Azeredo AB, Trent RB, Ellis A. Population-based analysis of 10,766 hospitalizations for mandibular fractures in California, 19911993. J Trauma 1998; 45(6): 1084-1087.

[16]. Hanson BP, Cumming P, Rivara FP, John MT. The association of third molars with mandibular angle fractures: a meta- analysis. J Can Dent Assoc 2004:70:39- 43.

[17]. Hassouni MK, Hamad SA. The relationship between fractures of the mandibular angle and the presence and position of mandibular third molars. Mustansiria Dent J 2005; 2(3):336-342.

[18]. Lida S, Hassfeld S, Reuther T, Nomura K, Mühling J. Relationship between the risk of mandibular fractures and the state of incompletely erupted mandibular third molars. J Cranio-Maxillofac Surg 2005; 33(3):158-163.

[19]. Nomura K, Okura M, Kogo M. Influence of the incompletely erupted lower third molar on mandibular angle and condylar fractures Trauma 2004;57:613-617.

[20]. Zhu SJ, Choi BH, Kim HJ, Park WS, Huh JY, Jung JH, Kim BY, Lee SH. Relationship between the presence of unerupted mandibular third molars and fractures of the mandibular condyle. Int J Oral Maxillofac Surg 2005;34:382-385.

[21]. Duan DH, Zhang Y. Does the presence of mandibular third molars increase the risk of angle fracture and simultaneously decrease the risk of condylar fracture? Int. J Oral Maxillofac Surg 2008; 37:25-28.

[22]. Knutsson K, Brehmer B, Lysell L, Rohlin M. Asymptomatic mandibular third molars: oral surgeons' judgment of the need for extraction. J Oral Maxillofac Surg 1992; 50:329-333

[23]. Peterson LJ. Principles of management of impacted teeth. In: Peterson LJ, Ellis E, Hupp JR, Ed: et al. Contemporary Oral and Maxillofacial Surgery. St. Louis, MO: Mosby 1993: 225-260.

\section{FIGURES:}

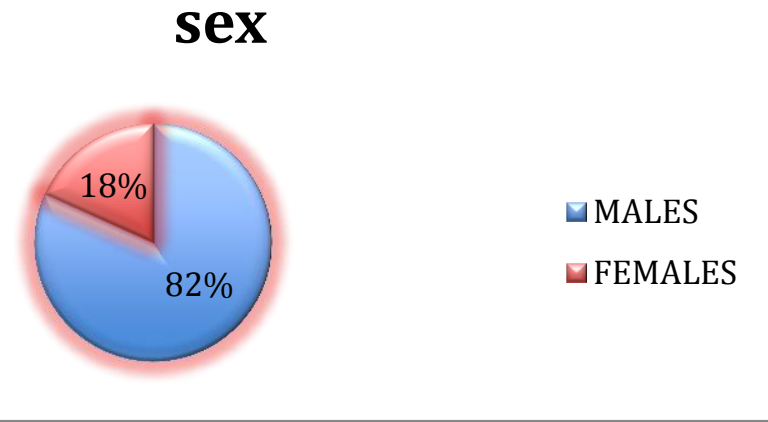

Fig: 1 Showing sex distribution of the cases in the study

\section{Chart Title}

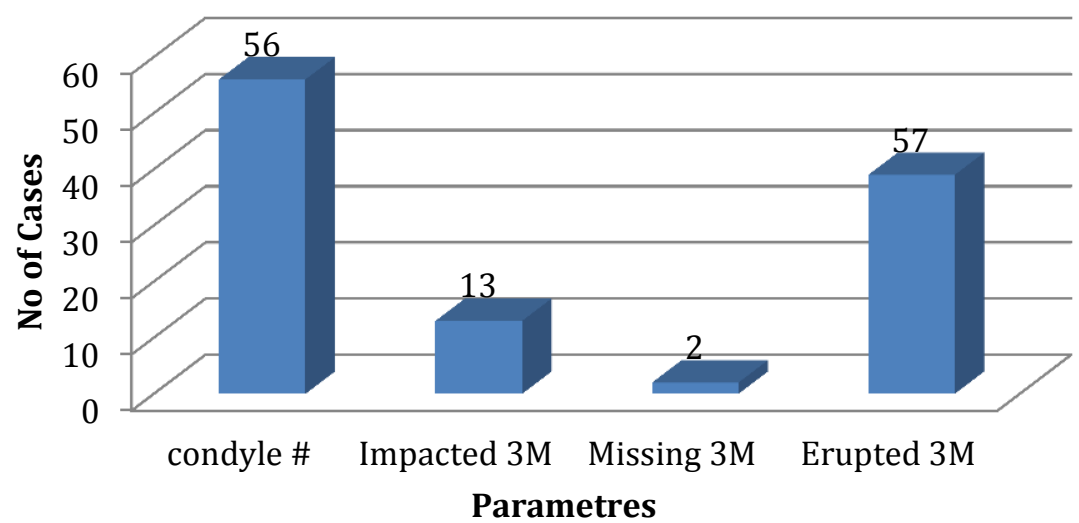


Fig 2: total cases and the various parameters assessed

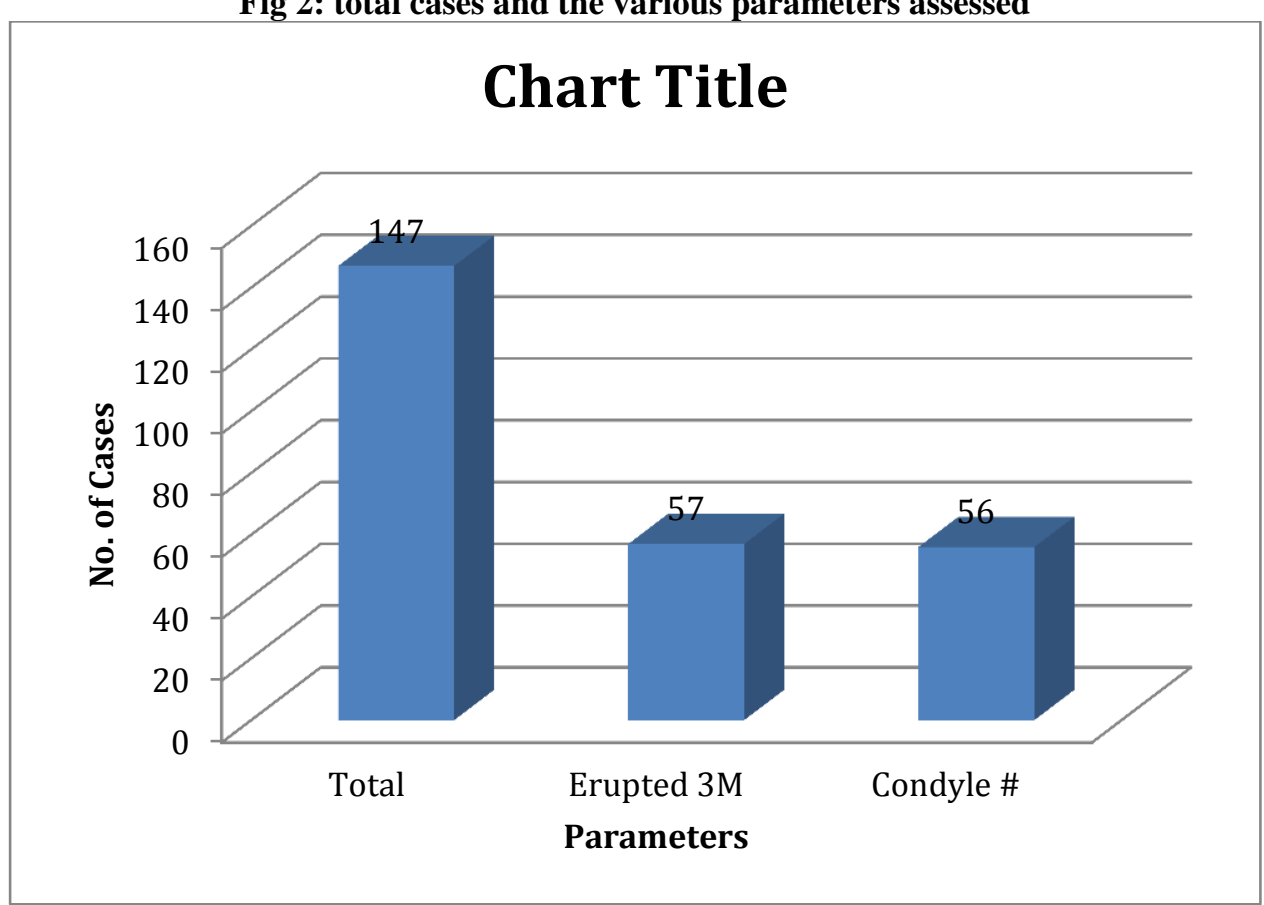

Fig3: showing the total no of erupted $3^{\text {rd }}$ molars $\&$ condyle fracture cases

\begin{tabular}{|c|c|c|c|}
\hline \multicolumn{2}{|c|}{ Factors } & $\begin{array}{c}\text { Spearman's correlation Co- } \\
\text { efficient (r) }\end{array}$ & P value \\
\hline Erupted 3M & CONDYLAR FRACTURE & 0.486 & $0.001^{* *}$ \\
\hline
\end{tabular}

Fig4: (showing Spearman's correlation test values) 